
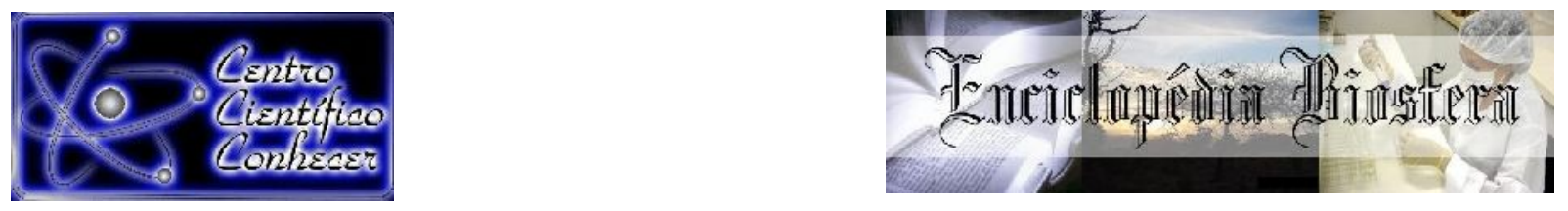

\title{
TENDINITE EM EQUINOS - ASPECTOS ANATÔMICOS, FISIOLÓGICOS E TERAPÊUTICOS
}

\author{
Natália Botega Pedroso ${ }^{1}$, Rilary de Oliveira Mapele ${ }^{1}$, Ivan de Souza Siqueira ${ }^{1}$, Júlia \\ Talita Caputo ${ }^{1}$, Matheus Camargos de Britto Rosa ${ }^{2}$. \\ - Acadêmicos (a) em Medicina Veterinária do Centro Universitário de Lavras \\ (UNILAVRAS), Lavras-MG, Brasil. \\ - Professor mestre do curso de Medicina Veterinária do Centro Universitário de \\ Lavras (UNILAVRAS), Lavras-MG, Brasil. \\ E-mail: matheusveterinaria@hotmail.com
}

Recebido em: 15/05/2021 - Aprovado em: 15/06/2021 - Publicado em: 30/06/2021

DOI: 10.18677/EnciBio_2021B23

\begin{abstract}
RESUMO
A tendinite é uma importante afecção dos equinos, principalmente em animais de corrida, causando grandes perdas econômicas. É definida como a inflamação dos tendões e pode ser causada por esforço excessivo, gerando sobrecarga no tecido. Claudicação é um dos sintomas marcantes da tendinite, mas pode não estar presente em todos os casos. Exames como radiografia, ultrassonografia e termografia têm sido usados para diagnóstico da doença. Com a evolução da medicina equina, diferentes técnicas de tratamento, como as terapias regenerativas, surgiram com o objetivo de promover a reabilitação completa do animal, e assim permitir que sua vida atlética seja prolongada e atinja grau de excelência dentro do esporte.
\end{abstract}

PALAVRAS-CHAVE: Claudicação; eqüinos; tendinite.

\section{TENDINITIS IN HORSES - ANATOMICAL, PHYSIOLOGICAL AND THERAPEUTIC ASPECTS}

\begin{abstract}
Tendinitis is an important disease of horses, especially in racing animals, causing great economic losses. It is defined as the inflammation of tendons and can be caused by excessive effort, generating overload in the tissue. Lameness is one of the outstanding symptoms of tendinitis but may not be present in all cases. Examinations such as radiography, ultrasonography and thermography have been used to diagnose the disease. With the evolution of equine medicine, different treatment techniques, such as regenerative therapies, have emerged with the aim of promoting the complete rehabilitation of the animal, and thus allow its athletic life to be prolonged and achieve excellence within the sport.
\end{abstract}

KEYWORDS: tendons; inflammation; lameness. 


\section{INTRODUÇÃO}

A tendinite em equinos causa perdas econômicas diretas e indiretas para proprietários espalhados em todo o mundo por ocasionar, muitas vezes, o fim da vida atlética do animal (MACHADO; CAMPEBELL, 2015). Muitos equinos, por esforço excessivo em práticas esportivas, têm diversas lesões, principalmente em tendões e ligamentos. A sobrecarga no tecido tendíneo promove danos físicos e degenerativos, devido ao uso além de sua resistência estrutural, o que permite a ocorrência de diversos problemas, como deslizamento fibrilar, quebra de reticulação e ruptura fibrilar, além de rompimento de toda a estrutura do tendão (ORTVED, 2018).

O tecido dos tendões é derivado de células mesenquimais e é composto, em sua maior parte, por colágeno do tipo 1. Normalmente, a ruptura das fibras de colágeno se deve por sobrecarga mecânica ou fadiga tendinosa crônica. Por serem tecidos organizados e que dependem da força e estrutura da matriz (MEC) para funcionar, ao sofrerem sobrecarga apresentam danos e até degeneração (CHEDID; MATHEUS, 2018). Os tendões possuem boa capacidade de cicatrização com o passar do tempo, porém, o tecido cicatricial apresenta qualidade biomecânica inferior ao tecido original podendo acarretar em reincidências da própria injúria ou claudicação (ORTVED, 2018).

Recentes avanços na medicina equina e nas técnicas de reabilitação do cavalo atleta, tornaram possíveis alto grau de excelência em relação ao esporte (JEUNE et al., 2015). Diversas técnicas foram desenvolvidas, com intuito do equino obter boa reabilitação, restaurando sua saúde com bons movimentos, atividade útil e construtiva (SCHLACHTER; LEWIS, 2016).

Em um estudo feito por Sousa et al. (2016) constataram que cavalos de corrida possuem maior prevalência de tendinite do que os demais, devido a maior exigência da musculatura. É importante o Médico Veterinário fazer sempre a escolha da melhor técnica terapêutica mediante ao caso específico de cada paciente (SCHLACHTER; LEWIS, 2016). Sendo assim, o objetivo da presente revisão é apresentar informações referentes a anatomia e fisiologia dos tendões, assim como sobre diagnóstico, prognóstico, tratamento e prevenção da tendinite nos equinos.

\section{Anatomia e Fisiologia}

O tendão é uma estrutura formada por tecido conjuntivo fibroso que tem como função transmitir a força do músculo ao osso. Essas unidades de tecido musculoesquelético possuem semelhança com os ligamentos e fáscias. Eles permitem o movimento de articulações, além de permitir a manutenção da postura corporal. Porém não possuem alta capacidade de alongamento, pois sua falência chega após um prolongamento de até $10 \%$ de seu tamanho, possuindo, alto grau de resistência, mas baixa extensibilidade. Eles são compostos de fibras colágenas paralelas, formando feixes bem agrupados que têm sua direção alterada conforme as aplicações de força da região (JUNQUEIRA; CARNEIRO, 1990; WHITING; ZERNICKE, 2001; NORDIN; FRANKEL, 2003; JARDIM, 2005; BISCIOTTI; VOLPI, 2016; ZACHARY, 2018). É uma estrutura muito resistente e forte, comparada ao osso, embora seja flexível e um pouco extensível (ZACHARY, 2018).

O colágeno tipo 1 constitui $80 \%$ do peso seco do tendão e é o principal componente fibrilar. Além dele, há presença do colágeno tipo 3, que faz parte do 
endotendão e do epitendão, conjunto de fibras e conjunto de fascículos de fibras, respectivamente. Ademais, os tendões são compostos de elastina, proteoglicanos, componentes inorgânicos e por células que se assemelham a fibroblastos (tenócitos), com formato de bastão ou fusiforme e que estão presentes numa matriz extracelular bem ordenada. A unidade musculotendinosa é composta de grande quantidade de água, representando cerca de $55 \%$ de seu peso total. Esse líquido tem como objetivo principal reduzir a ficção, tornando mais fácil o deslizamento das fibrilas, quando aplicada uma força mecânica (ZACHARY, 2018).

Os tendões possuem baixa vascularização, e essa é originária de vasos que penetram o paratendão (bainha de tecido conectivo frouxo que envolve o tendão) vindas do perimísio e periósteo, sendo a junção tenoóssea de importância singular na vascularização dos tendões. Além disso, a bainha sinovial envolta do tendão, possui aspectos relacionados a nutrição tendínea (PAYNE; TOMLINSOM, 1993; NORDIN; FRANKEL, 2003; BICIOTTI; VOLPI, 2016). Outra característica dos tendões maduros é sua constituição ser, em sua maioria, formada por fibrócitos quase inativos, que possuem baixa capacidade de sintetizar proteína fibrosa ou dividir-se, reduzindo drasticamente a capacidade do tecido de unir dois segmentos rompidos, dificultando a cicatrização. Quando há cicatrização, a maior parte da síntese e deposição de colágeno é feita por células extrínsecas (PEACOCK; VAN WINKLE, 1976).

$\mathrm{Na}$ presença de trauma, o tecido tendíneo tem tendência a apresentação de aderência. No entanto, para recuperação da função deslizante do tendão, não se deve prevenir totalmente as aderências teciduais, mas sim reduzir sua proporção no tecido cicatricial. Para tal, deve-se evitar hematomas, formação de abcessos, sendo recomendado repouso. Por outro lado, se houver a ruptura de aderências em seu estágio inicial, a inflamação aumenta e, posteriormente, haverá nova cicatrização (PEACOCK; VAN WINKLE, 1976; JOHNSTON, 1985).

\section{A tendinite}

O processo inflamatório dos tendões é chamado de tendinite e acontece quando há esforço exagerado de extensão. Isso causa distensão das fibras e, consequentemente, uma reação inflamatória que pode ser extremamente dolorosa e severa no local (THOMASSIAN, 2005; MACHADO; CAMPEBELL, 2015; BISCIOTTI; VOLPI, 2016).

Normalmente os tendões mais acometidos pela tendinite são os flexores, com a inflamação podendo se estender as suas respectivas bainhas sinoviais. Nos cavalos de corrida, os membros torácicos são os mais acometidos, enquanto nos animais de tração ou sela são os membros pélvicos. Como os membros torácicos sustentam grande parte do peso e impacto durante as corridas e saltos, eles sofrem mais lesões. Os danos comumente acontecem na região central da porção metacarpiana média do tendão flexor superficial do dedo, pois durante o galope a articulação metacarpofalangeana é hiperextendida, submetendo-o a alta tração (MACHADO; CAMPEBELL, 2015). Além disso, fatores como treinamentos forçados e feitos de maneira inadequada, fadiga muscular, ferrageamento errôneo, início de treinamento precoce, estrutura do solo, estado corpóreo (obesidade) e defeitos de aprumos, podem predispor o equino a apresentar tendinite (THOMASSIAN, 2005). 
A lesão pode ocorrer de duas formas principais. A primeira é chamada de lesão singular, onde um episódio específico traz inflamação a região, podendo ser causada por trauma; já a forma contínua, se trata de um processo no qual microlesões ocorrem em intervalo maior de tempo, gerando a tendinite. No entanto, ambos os tipos de lesões podem levar ao rompimento parcial ou total do tendão (MACHADO; CAMPEBELL, 2015).

O processo cicatricial é dividido nos tendões em fase inflamatória aguda, onde ocorre fagocitose do tecido rompido e demarcação da parte lesionada do tecido; fase proliferativa, com formação de tecido fibroproliferativo; fase de remodelação, em que as fibrilas colagenosas são organizadas no formato de feixes de tendões. Com relação ao tempo de cada fase, em média, a fase aguda dura de 10 a 14 dias, a fase proliferativa de 4 a 45 dias e a fase de remodelamento de 45 a 120 dias (BISCIOTTI; VOLPI, 2016; CHEDID; MATHEUS, 2018).

Para prevenção, é necessário manter os animais que são frequentemente acometidos por lesões tendíneas em observação minunciosa e constante. E importante a realização de uma rotina de treinos metódica com esses animais, que devem receber, após as atividades físicas, duchas nos membros para prolongar sua vida atlética. Além do mais, para redução da tensão de tração sob o tecido, pode ser utilizada ferradura de trabalho talonada (THOMASSIAN, 2005).

\section{Patogenia}

Como já dito, a tendinite ocorre mais nos tendões flexores em relação aos demais, principalmente nos tendões flexor superficial do dedo e flexor profundo do dedo (CHEDID; MATHEUS, 2018; BECCATI et al., 2018). Quanto à anatomia e localização desses dois componentes, é importante dizer que os equinos não possuem músculos distalmente aos ossos do carpo e do tarso, apenas tendões e ligamentos que se conectam a músculos que têm posição proximalmente a essas articulações. O tendão flexor superficial do dedo está localizado sob a pele e, próximo aos ossos sesamoides proximais, um anel fibroso está anexado a sua borda (manga flexória) e circunda o tendão flexor profundo do dedo (EL-SHAFAEY et al., 2016).

Em relação a patogenia, o trauma nos tendões pode ser por hiperextensão, produzindo lesão microscópica, ou por ação traumática aguda, o que gera lesões macroscópicas com rompimento do tendão. Respostas degenerativas caracterizadas por exsudação e de reparação caracterizadas por granulação, ocorrem em toda ação traumática nos tendões, seja ela micro ou macroscópica. Esses processos estão relacionados por presença de vascularização proveniente de músculos, ossos, bainhas sinoviais ou paratendão nos tendões que não possuem bainha (THOMASSIAN, 2005; CHEDID; MATHEUS, 2018; BECCATI et al., 2018).

A característica de degeneração do tendão flexor superficial do dedo é uma descoloração em sua região central. Já no processo cicatricial, a necrose tendínea e a formação de coágulo de fibrina pode causar distúrbios, como a não cicatrização (THOMASSIAN, 2005; CHEDID; MATHEUS, 2018; BECCATI et al., 2018). Ademais, a vascularização de um tendão lesionado, por apresentar intensa angiogênese, forma vasos com conformação anárquica e, normalmente, esta neovascularização corre paralela ao colágeno (BISCIOTTI; VOLPI, 2016). 
Geralmente, o acúmulo de diversos microdanos causados pela sobrecarga e a alta tensão que culminam em lesões. O processo também é responsável por aumentar a prevalência de afecções com o passar da idade do animal (CHEDID; MATHEUS, 2018). Quando o equino sofre uma lesão muscular devido à sobrecarga de exercícios, por exemplo, ocorrem microdanos, que dão origem a inflamação neurogênica associada a dor, contudo, caso não haja rompimento, a dor irá diminuir e, posteriormente, a inflamação irá se prolongar, levando a adaptação fisiológica (BISCIOTTI; VOLPI, 2016).

\section{Sinais clínicos}

Os sinais de claudicação, edema, aumento de temperatura, dor a palpação, mesmo que superficial, se iniciam logo após o trauma. Além do acometimento dos tendões, pode haver lesão no músculo interósseo, o que caracteriza uma afecção chamada desmite interóssea (THOMASSIAN, 2005).

Durante a movimentação do animal é importante analisar seu comportamento na saída da baia, sua marcha durante o exercício e o retorno a baia, pois o animal com tendinite pode apresentar amplitude de marcha comprometida. Exames em posição quadrupedal devem ser feitos de maneira ampla, com palpação da área afetada, exames dos cascos e dos movimentos dos tendões, pois quando há presença de tendinite, o equino tende a apresentar sinais clínicos diversos (MCLLWRAITH, 2015; CHEDID; MATHEUS, 2018).

Sinais como edema local, aumento de temperatura, dor a palpação e claudicação são os mais observados nos animais com tendinite encaminhados ao Médico Veterinário. A claudicação, no entanto, não é obrigatória, pois está diretamente relacionada com o grau de inflamação do tendão. Mas após atividade física, a claudicação é mais fácil de ser observada, podendo ser avaliada e quantificada, estabelecendo-se o tratamento mais adequado (MACHADO; CAMPEBELL, 2015).

A claudicação, como já dito, é um sinal clínico da tendinite, mas também pode estar relacionada a outros tipos de lesões. Trata-se de postura ou marcha anormal, demonstrando assim uma manifestação de dor, déficit neuromuscular ou disfunção mecânica. Quando o cavalo está claudicando, além de sua postura ficar instável, há falta de equilíbrio e simetria. Além disso, a claudicação pode ser quantificada em graus 0 (não perceptível em nenhuma circunstância), 1, 2, 3, 4 e 5 (suporte mínimo de peso no membro acometido ou incapacidade de locomoção) (DAIVIDSON, 2018).

O diagnóstico de lesões tendíneas subclínicas é difícil devido à ausência de sinais clínicos claros. No âmbito crônico da doença, geralmente há edema por fibrose e inflamação palmar mas, frequentemente, permanece indolor, com redução na movimentação devido a formação de aderências com o paratendão dos tendões flexores (THOMASSIAN, 2005; MACHADO; CAMPEBELL, 2015; CHEDID; MATHEUS, 2018).

Ainda se tratando da tendinite crônica, pode-se dizer que esta é uma evolução da fase aguda devido ao tratamento negligenciado, feito de forma insuficiente ou malconduzido. Nesse caso, a claudicação durante o trote é discreta e aparece apenas como um atraso na elevação do membro. Pode haver também restrições de movimento por aderências no paratendão, ligamentos ou bainhas, prejudicando a função dos 
tendões flexores. Ademais, o ligamento anular pode estar comprometido devido à constrição (THOMASSIAN, 2005).

\section{Diagnóstico}

Entre os meios de diagnóstico da tendinite estão inclusos a anamnese completa, exames físicos e exames complementares. Na anamnese, devem ser coletadas informações relacionadas ao histórico do animal, principalmente o histórico da lesão. Posteriormente, é feito o exame físico, incluindo a inspeção, palpação e manipulação do membro. Primeiramente, a inspeção do membro é feita com o animal em posição quadrupedal, analisando os ângulos, conformação e distribuição de peso, realizando-se em seguida o exame com o animal em movimento. Na palpação dos tendões, é importante verificar a temperatura local, aumento de volume e a presença de dor. A palpação tendínea deve ser realizada com o membro em apoio e em flexão passiva (THOMASSIAN, 2005; CHEDID; MATHEUS, 2018).

Em relação aos exames complementares, os mais utilizados são a ultrassonografia, radiografia, bloqueio perineural e a termografia, sendo o ultrassom o mais comum e com maior relevância para essa lesão (CHEDID; MATHEUS, 2018).

\section{Ultrassom}

Para realização do exame ultrassonográfico 0 animal deve ser contido adequadamente, sendo fundamental a realização de tricotomia e uso de gel no local. É necessária a visualização do tendão em planos transversais e longitudinais, para avaliar tamanho, forma, localização, ecogenicidade e padrão das fibras. Para analisar as imagens, é importante conhecer os padrões normais dos tendões saudáveis, que possuem em comum uma estrutura fina com fibras paralelas e hiperecoicas. Quando o animal possui tendinite, a imagem fica alterada e varia de acordo com a fase de cicatrização do tendão (COOK, 2016; BERNER, 2017).

$\mathrm{Na}$ fase aguda da tendinite ocorre inflamação reativa, com 0 tendão apresentando aumento de tamanho e há perda focal ou difusa da ecogenicidade normal (hipoecoica), devido a hemorragia, edema ou ruptura fibrilar (BAXTER, 2020). É importante a comparação entre os membros colaterais quando for um caso unilateral para analisar a área do tendão (THOMASSIAN, 2005; LAVOIE; HINCHCLIFE, 2008; COOK, 2016; BERNER, 2017).

$\mathrm{Na}$ fase de proliferação, em que há formação de hematoma e tecido de granulação imaturo, a imagem fica hipoecoica e a lesão aumenta de tamanho devido a hemorragia e inflamação. Dessa forma, o reconhecimento fica mais visível após dez dias de lesão (BERNER, 2017). Já nas fases de remodelação e maturação tendínea, considerada a fase crônica da lesão, a imagem possui ecogenicidade heterogênea. Nestas fases, ocorre a substituição do tecido cicatricial imaturo por tecido maturo, alterando o padrão das fibras que ficam desalinhadas e irregulares, havendo formação de áreas hiperecoicas, o que indica uma possível calcificação (LAVOIE; HINCHCLIFE, 2008; BERNER, 2017; CHEDID; MATHEUS, 2018).

Vale ressaltar que o animal deve ser avaliado com o membro suportando o seu peso, evitando interpretação errônea devido ao relaxamento tendíneo ao não apoiar o membro (BAXTER, 2020). Dito isso, é possível observar a importância da 
ultrassonografia não somente para diagnosticar a injúria, como também para acompanhar a cicatrização da lesão, sendo importante realizar exames a cada três meses (BERNER, 2017) e, dessa forma, orientar a reabilitação do paciente de maneira mais segura (REDDING, 2020).

\section{Radiografia}

O diagnóstico por radiografia não é comumente utilizado, mas é uma alternativa, principalmente para diferenciação de lesões nos sesamoides. Os achados são, especialmente, mineralização e irregularidade óssea na inserção do tendão (THOMASSIAN, 2005; LAVOIE; HINCHCLIFE, 2008).

\section{Bloqueios perineurais}

Nas tendinites com sinais clínicos sutis ou ausentes, o diagnóstico pode ser feito através de bloqueio anestésico perineural, fazendo analgesia nas regiões afetadas (LAVOIE; HINCHCLIFE, 2008). O bloqueio consiste em uma técnica diagnóstica para claudicação, que permite a confirmação do local de origem da dor (BACCARIN et al., 2015; DAVIDSON, 2018). A técnica anestésica é feita através da aplicação de anestésicos locais, podendo ser cloridrato de lidocaína $2 \%$ ou mepivacaína $2 \%$, realizando um bloqueio reversível de impulsos nervosos na área aplicada. Isto significa que após a aplicação há recuperação completa da função nervosa sem nenhum tipo de dano e, dessa forma, quando aplicada no local da lesão, interrompe a claudicação do animal (SPINOSA et al., 2006).

Antes da introdução da agulha para aplicação do anestésico, é muito importante realizar a antissepsia local com iodopovidona ou clorexidina degermante e finalizar com álcool etílico $70 \%$. Vale salientar que o bloqueio deve começar distal e ir progredindo proximal aos ramos nervosos para assim não mascarar o local originário da dor e claudicação (BACCARIN et al., 2015).

\section{Termografia}

O diagnóstico por meio da termografia é feito por uma representação da temperatura superficial de um objeto (TURNER, 2020). É um método não invasivo que auxilia no diagnóstico precoce da lesão, por meio da mensuração do calor emitido, tendo em vista que há elevação da temperatura em até duas semanas antes do início dos sinais clínicos (SOROKO; KROWELL, 2016; TURNER, 2020).

A interpretação da termografia se baseia nas características circulatórias que ditam o padrão térmico. Dessa forma, quando ocorre lesão tecidual, há alteração na circulação sanguínea do local, devido ao processo inflamatório que gera calor. Para uma interpretação correta é necessário que o animal seja imobilizado em ambiente protegido dos raios solares, tendo em vista que este fator pode influenciar na temperatura, alterando o resultado. Sendo assim, os tendões com tendinites agudas apresentam ponto quente sob o local da lesão e conforme vai cicatrizando, o padrão se torna mais uniforme, porém permanece anormal em relação ao tendão sem nenhuma lesão (TURNER, 2020). 


\section{Ressonância magnética}

Existe ainda o diagnóstico por ressonância magnética, em que uma imagem transversal multiplanar utiliza propriedades magnéticas teciduais para caracterizar melhor as lesões tendíneas agudas ou crônicas. Entretanto, devido ao seu elevado valor e falta de acesso a essa modalidade diagnóstica, é pouco utilizado na rotina clínica de equinos (SCHRAMME; SEGARD-NEISSE, 2020).

\section{Diagnósticos diferenciais}

Os principais diagnósticos diferenciais para a tendinite são a desmite de suspensório, desmite inferior, desmite plantar longa, tenossinovite primária (não infecciosa), síndrome do ligamento anular palmar e plantar e, principalmente, lesões de sesamoide (THOMASSIAN, 2005; LAVOLE; HINCHCLIFE, 2008).

\section{Tratamento}

Para o tratamento da tendinite o importante é a limitação do processo inflamatório, controle da dor, prevenção de lesões adicionais e início do tratamento em estágios iniciais (LAVOIE; HINCHCLIFE, 2008), fazendo com que o cavalo retorne ao seu nível atlético anterior e também evitando recidivas (ORTVED, 2018). É necessário que o animal fique em descanso até o desaparecimento da inflamação aguda, que leva cerca de 30 dias (BAXTER, 2020).

Os diferentes tratamentos têm como objetivos principais diminuir a inflamação (que embora necessária para o processo, se muito severa pode causar danos), a formação de tecido cicatricial que normalmente se instala como uma massa de tecido fibroso e desorganizado, e ajudar na restauração da função tendínea normal (ALVES et al., 2002).

\section{Tratamentos convencionais}

Como tratamentos convencionais são indicados repouso do animal, aplicação local de gelo, duchas com águas frias, massagens locais, ligas de descanso e imobilização de membros. O uso de gelo e duchas de água fria são importantes para diminuir o edema, necrose celular secundária, inflamação e dor, devendo a aplicação ser por 20 minutos, três vezes ao dia. As massagens podem ser associadas a fármacos como o dimetilsulfóxido, dexametasona ou triancinolona durante cinco a sete dias. Além disso, o uso concomitante de anti-inflamatórios não esteroidais, como a fenilbutazona (2,2 a $4,4 \mathrm{mg} / \mathrm{kg} / \mathrm{SID}$ ou BID/IV ou VO) ou flunixin meglumine $(1,1 \mathrm{mg} / \mathrm{kg} / \mathrm{SID} / \mathrm{IV})$ é importante para minimizar a formação de tecido cicatricial, reduzindo a inflamação e promovendo analgesia ao animal (NAVIAUX, 1988; THOMASSIAN, 2005).

Não é recomendado o uso de corticoides sistêmicos, pois prejudicam a resposta inicial de cura (BAXTER, 2020). O hialuronano e os glicosaminoglicanos polissulfatados podem ser associados aos tratamentos, pois possuem bons efeitos na redução de aderências e promoção matriz extracelular de qualidade (BAXTER, 2020).

Estes tratamentos convencionais aumentam as chances do equino retornar a sua atividade em um nível igual ou semelhante ao anterior à injúria e com menor risco de recidivas. Para tal, é importante conciliar a retomada dos exercícios de forma gradual e controlada, fazendo o acompanhamento do animal por ultrassonografia tendínea de 30 
a 60 dias após a lesão e regressão dos sinais clínicos. O tempo do tratamento vai variar de acordo com a gravidade, localização e extensão da injúria (LAVOIE; HINCHCLIFE, 2008).

\section{Terapias celulares}

\section{Plasma rico em plaquetas}

Atualmente existem novas terapias que podem auxiliar no tratamento da tendinite como, por exemplo, as terapias regenerativas que têm como principal função a criação de tecidos que substituam ou restauram os tecidos originais ausentes, perdidos ou danificados por diferentes traumas. Os tecidos devem ser semelhantes ao de origem, para possibilitar o retorno dos equinos ao seu nível atlético normal, além de evitar recidivas. Essas terapias fornecem autocura por recrutamento de células endógenas ou aplicação de células exógenas (DAHLGREN, 2018; ORTVED, 2018). As principais terapias regenerativas são a aplicação de plasma rico em plaquetas e de células-tronco (DAHLGREN, 2018; ORTVED, 2018).

O plasma rico em plaquetas (PRP) é uma preparação biológica autóloga que possui contagem de plaquetas maior que a do sangue total, sendo a concentração de plaquetas acima de 300.000 L (ANITUA et al., 2004; ORTVED, 2018; ALVARENGA, 2020). Ainda não existe um protocolo ideal para produção de PRP, tendo em vista que possuem diversas formas. De maneira geral, todos se baseiam na coleta de amostra sanguínea e concentração das plaquetas por processo de filtragem ou centrifugação (ALVARENGA, 2020).

O PRP apresenta um papel importante como agente regenerador, pois contém fatores de crescimento fundamentais na regulação inflamatória e estrutural dos tecidos. Esses fatores de crescimento são liberados devido à degranulação das plaquetas. Dessa forma, o PRP promove a cura melhorando a migração, proliferação e diferenciação celular, o que aumenta a força e elasticidade dos tendões. Além disso, estudos recentes mostram resultados positivos através de uma única aplicação, além de ter menor custo financeiro (ORTVED, 2018; BONILLA-GUITIÉRREZ; LÓPEZ; CARMONA, 2019).

Pesquisas visando comprovar a eficácia do uso do PRP no tratamento de tendinites em equinos foram feitas avaliando o processo de cicatrização do tendão. Sendo assim, o sucesso terapêutico foi mensurado através da funcionalidade do animal, ou seja, verificando o grau de claudicação, recorrência e testes biomecânicos dos membros. Dessa forma, os animais tratados com PRP tiveram redução precoce da claudicação. Por meio da palpação foi possível verificar queda precoce da temperatura local, com as imagens ultrassonográficas mostrando o reparo avançado. Os animais tratados com PRP apresentaram desempenho atlético igual ou superior ao anterior a lesão após um ano do tratamento (GEBUREK, 2016).

\section{Células tronco}

As células-tronco (CT), são células indiferenciadas progenitoras multipotentes com elevada capacidade de auto renovação e de diferenciação em diferentes células construtivas de tecidos distintos e proliferação. Atualmente existem diferentes tipos de 
CT, dependendo do seu potencial de diferenciação e multiplicação (ORTVED, 2018; BONILLA-GUITIÉRREZ et al., 2019; ALVARENGA, 2019).

As células-tronco embrionárias (CTE), que possuem elevado potencial de diferenciação e multiplicação, são classificadas como totipotentes e pluripotentes, devido a capacidade de gerar todos os tecidos de um organismo. Entretanto existem diversas questões éticas e de segurança que devem ser consideradas para seu uso e, portanto, não é utilizada na rotina clínica como opção terapêutica (ALVARENGA, 2019).

Outro tipo de CT são as encontradas em tecidos já diferenciados ou adultos e estão presentes em todos tecidos dos organismos. Existem algumas classificações de acordo com o potencial de diferenciação, sendo unipotentes aquelas que originam somente um tipo celular ou multipotentes as que originam uma linhagem celular como ossos, cartilagens e tendões (BRANDÃO, 2018; ORTVED, 2018). Entre as multipotentes se encontram as células-tronco mesenquimais (CTMs), que são células indiferenciadas de origem mesodermal (ALVARENGA, 2019), sendo as mais utilizadas para tratamento de tendinites, devido a facilidade em isolamento e expansão in vitro (TORRES-TORRILLAS, 2019).

As CTMs podem ter diferentes origens, mas as originárias da medula óssea e do tecido adiposo tem uso mais frequente. Em equinos, a coleta de medula óssea é geralmente realizada no esterno ou da tuberosidade do íleo. A coleta, que pode ser do próprio paciente (autóloga) ou de animais doadores (alogênica), é realizada sob orientação ultrassonográfica, com o animal em posição quadrupedal e sedado. Já a coleta de tecido adiposo, é realizada no tecido subcutâneo na base da cauda, procedimento também realizado através da sedação do animal, em posição quadrupedal e com bloqueio local de pele. Este último é mais acessível e possui menor risco de rejeição, possuindo a desvantagem de formação cicatricial mais acentuada (ALVARENGA, 2019; TORRES-TORRILLAS, 2019).

Após a coleta, o fragmento ou aspirado é enviado para laboratório especializado em cultivo celular, onde vão ser submetidos ao processo de fração mononuclear, no caso da medula óssea ou estromal do tecido adiposo e são cultivados por cerca de 3 a 4 semanas (ALVARENGA, 2019). As CTMs devem ser aplicadas de forma intratecal, na região do tendão, para que atue no local da lesão (STEWARD; GOODRICH, 2020).

As CTMs possuem propriedades imunomoduladoras das células $T$ reguladoras e regenerativas, possuindo alto potencial terapêutico, modulando a inflamação, curando e reparando o tendão após a lesão (BRANDÃO, 2018; ORTVED, 2018). As CTMs promovem imunossupressão local que estimula os mecanismos de regeneração, com produção de anti-inflamatórios, imunorreguladores e fatores de crescimento (BRANDÃO, 2018).

Como uso de CTMs ainda é recente, a dose e intervalo ideais são desconhecidos (ORTVED, 2018), entretanto, de acordo com Baxter (2020), em tendinites o uso deve acontecer a cada 30 dias, variando de três a quatro aplicações no animal. Em estudos já realizados, cavalos em tratamento com CTMs apresentam melhora que pode ser observada histologicamente e através da ultrassonografia (COBALTH, 2017).

Ainda existem alguns desafios quanto à utilização de CT, principalmente devido à dificuldade em avaliar sua eficácia e o momento de aplicação das células, que apresentam maior resultado após a fase inflamatória (SHOJAEE; PARHAM, 2019). 
Diversos estudos demonstram que a associação do plasma rico em plaquetas com as células-tronco é benéfica e otimiza resultados de ambas as opções terapêuticas, aumentando assim, a taxa de sucesso (ALVARENGA, 2020).

\section{Fisioterapia e reabilitação}

Outras terapias utilizadas para o tratamento de tendinite, estão associadas a fisioterapia e reabilitação para reparação tendínea (ORTVED, 2018). Nesse contexto, as mais utilizadas são a terapia térmica por frio (crioterapia), ultrassonografia terapêutica, ondas de choque (ESWT), exercícios controlados e laserterapia (KANEPS, 2016; SCHALACHTER, LEWIS, 2016; ORTVED, 2018). A fisioterapia e reabilitação têm como objetivos restaurar o movimento e a função dos tendões, proporcionando ao animal uma melhor condição de saúde (MCGOWAN; CONTRTRIALL, 2016; SCHLACHTER; LEWIS, 2016).

\section{Crioterapia}

A terapia térmica por frio, também conhecida como crioterapia, é uma forma terapêutica bem comum, que teve início na Grécia Antiga, onde os gregos utilizavam em locais de inflamação. Entretanto, somente na década de 60 teve início da terapia do primeiro ao terceiro dia pós trauma (KNIGHT, 2000).

As principais funções terapêuticas estão relacionadas a redução da dor por decorrência da diminuição da transmissão nervosa das fibras de dor e redução da excitabilidade dos sensores terminais, além também de promover redução de edema local, através da vasoconstrição realizada pelo gelo, reduzindo a temperatura tecidual, hemorragia e extravasamento de células inflamatórias (NAVIAUX, 1988).

Esse método possui maior eficiência na fase aguda da tendinite. A crioterapia pode ser utilizada pela imersão do membro em água gelada, sendo este mais eficaz, ou por uso de compressas de gelo ou frias. O animal deve permanecer cerca de 20 a 30 minutos em contato com o gelo para obter o efeito desejado (KANEPS, 2016; ORTVED, 2018). Vale salientar que seu uso exige um conhecimento teórico da terapia, principalmente em relação ao tempo de exposição para evitar efeitos colaterais (ALLGAYER, 2019).

\section{Ultrassom terapêutico}

A ultrassonografia terapêutica de baixa frequência é uma forma de energia acima de $20000 \mathrm{~Hz}$, imperceptível ao ouvido humano, em que ondas sonoras desfocadas podem penetrar tecido adjacentes, estimulando a cicatrização, analgesia, redução de edema tecidual e cicatrização fibrosa (KANEPS, 2016; SCHALACHTER, LEWIS, 2016). Além de ser classificado como uma terapia não invasiva, é bem tolerada pelos animais, não sendo necessária a sedação (KANEPS, 2016).

A indicação do uso se baseia na compressão e vasodilatação produzida, pois o ultrassom fornece energia devido ao aumento do metabolismo celular, elevando a demanda de oxigênio, o que melhora a cicatrização (SCHALACHTER, LEWIS, 2016).

Para geração de efeitos adequados, deve ser realizada tricotomia no local e aplicação de gel para facilitar o contato entre a pele e o transdutor (ALLGAYER, 2020). Ademais, sua utilização deve ser feita durante a fase proliferativa da cicatrização para 
liberação de fatores de crescimento, na fase de remodelação para aumentar a resistência à tração do colágeno e, consequentemente, melhorar o padrão e orientação das fibras (CARROZZO et al., 2019; KOCH; GOODRICH, 2020).

Existem duas modalidades para o ultrassom terapêutico: o modo contínuo e o modo pulsado. O primeiro gera um efeito térmico através das vibrações de moléculas, sendo indicado para processos crônicos. No modo pulsado formam-se efeitos mecânicos no tecido alvo que geram bons resultados em processos agudos e subagudos. Este método acarreta em proliferação de fibroblastos, osteoblastos e monócitos, angiogênese e deposição de colágeno (LEVINE et al., 2008; ALLGAYER, 2020).

\section{Ondas de choque}

O tratamento por ondas de choque (ESWT) envolve aplicação de energia eletromagnética convertida em ondas de choque de pressão de alta energia em picos transitórios, seguida por pressão negativa e retornam a pressão zero $(\mathrm{KOCH}$; GOODRICH, 2020). A pressão aumenta enquanto os tecidos são movimentados e são produzidos micro traumas importantes para o aumento do fluxo sanguíneo na região. Nesse processo, ocorre redução dos mediadores inflamatórios, o que amplia o número de citocinas angiogênicas, proliferação de vasos sanguíneos e fatores de crescimento que proporcionam a cicatrização e regeneração dos tecidos ósseos, musculares e tendíneos, além de expandir o número de osteoblastos e recrutar células-tronco mesenquimais. Sendo assim, o ESWT causa analgesia, atingindo o pico após 48 horas do tratamento (KANEPS, 2016; SCHALACHTER, LEWIS, 2016; ORTVED, 2018).

Para um efeito mais eficaz, é necessária a tricotomia no local e aplicação de gel. Deve haver um manejo adequado do animal submetido a essa terapia, pois pode causar uma desorganização no colágeno e rachaduras no osso, devendo o animal ter uma restrição ao exercício após a aplicação (KANEPS, 2016; SCHALACHTER, LEWIS, 2016; ORTVED, 2018).

Em um estudo feito com animais com desmite do ligamento suspensório foi comprovada a clara eficácia da recuperação dos tecidos desses animais. Os autores constataram que $79 \%$ dos animais estudados apresentaram retorno completo a todas as atividades antes realizadas pelos animais depois de apenas um ano de tratamento (GIUNTA et al., 2019). O mesmo estudo relatou que houve ainda maior efeito do tratamento com ondas de choque quando comparado ao uso da técnica do plasma rico em plaquetas; esse resultado, cabe ressaltar, foi observado tanto a longo como a curto prazo.

\section{Laserterapia}

O tratamento com laser de baixo nível é semelhante a ultrassonografia terapêutica, promovendo efeitos anti-inflamatórios e analgésicos por estimularem o metabolismo celular e atividade fibroblástica. Ocorre a modulação de prostaglandinas E2, fator de necrose tumoral-alfa e interleucina-1B, reduzindo a inflamação. Para a tendinite, seu efeito mais importante é a proliferação celular e síntese de colágeno, o que leva a rápida melhora do tecido danificado (McGOWAN; GOLFF, 2016; SCHALACHTER; LEWIS, 2016; ALLGAYER, 2019). 
O efeito da laserterapia ocorre através de moléculas cromóforas, como a hemoglobina e a melanina, encontradas no interior de mitocôndrias, que geram um efeito de fotobioestimulação, acarretando efeitos biológicos específicos. A energia transmitida pelo laser (energia fotônica) se transforma em energia bioquímica, através de fotorreceptores mitocondriais, que vão aumentar a reação do citrocromo $C$, o que eleva a taxa de respiração celular, libera óxido nítrico e produz ATP. Dessa forma, ocorrem as modulações de funções celulares e estimulação de mecanismos de reparo tecidual. Quando usado sinergicamente com o PRP, o laser ajuda a evitar recidivas (Mc GOWAN; GOLFF, 2016; SCHALACHTER; LEWIS, 2016; ALLGAYER, 2019).

No caso relatado por Bandeira et al. (2020) o animal estava com uma ferida de grau 4 atingindo todas as camadas de pele e tecidos adjacentes, como músculo e tecido subcutâneo, após limpeza e retirada de tecido morto, instituiu-se o tratamento com terapia a laser feita segundo o seguinte protocolo: 10 sessões iniciais divididas em semanas, sendo três sessões por semana com um aparelho que emitia 584 pulsos por minutos. Após as 10 iniciais, houve necessidade, após avaliação, de mais oito sessões divididas da mesma forma que as 10 primeiras. Contatou-se que o tempo de cicatrização da ferida foi muito reduzido e seis semanas após o primeiro atendimento, ao final do tratamento, a cicatriz ficou pequena e a ferida totalmente fechada.

\section{Reabilitação}

Os animais, além de todas essas terapias, devem receber um programa de exercícios adequado, com retorno aos poucos após a lesão, consistindo este o principal fator para levar o animal ao seu bom nível atlético (KANEPS, 2016; ORTVED, 2018). É necessário primeiro um descanso, até que a inflamação aguda desapareça e, em seguida, um retorno gradual aos exercícios (BAXTER, 2020). Os exercícios vão de acordo com a melhora do animal, iniciados com caminhadas leves de 15 a 30 minutos diários (KANEPS, 2016).

É de suma importância que o animal se exercite de forma leve, mas sempre caminhando para incentivar o alinhamento ideal das fibras e evitar aderências restritivas (KANEPS, 2016; ORTVED, 2018). De acordo com o progresso da imagem ultrassonográfica e da claudicação, os exercícios são aumentados gradativamente em intensidade e duração. Vale ressaltar que o encurtamento do período de descanso e avanço rápido dos exercícios podem resultar no agravamento das lesões tendíneas (BAXTER, 2020).

\section{Tratamentos cirúrgicos}

Baxter (2020) descreve dois tratamentos cirúrgicos para tendinites em tendões flexores superficial, que inclui a divisão do tendão e transecção do ligamento acessório proximal. Ainda de acordo com o mesmo autor, a divisão longitudinal se baseia na compressão da lesão, fornecendo um canal de vascularização para lesões centrais e promoção de cicatrização. Vale salientar que as fibras tendíneas não são seccionadas e sim separadas, para não ocorrer agravamento nos danos. Já a transecção do ligamento acessório superior, libera o tendão flexor superficial do dedo e forma-se uma 
lacuna no local, que altera as forças biomecânicas e diminui as cargas de pico no tendão (BAXTER, 2020).

Há outro método, denominado técnica splitting, utilizada no tratamento de algumas afecções tendíneas para estimular a vascularização e, consequentemente, melhorar quadros de regeneração tecidual. Essa técnica de perfuração tendínea faz com que, ao se fazer incisões na lesão, aconteça comunicação entre os outros tecidos ao redor, isso favorece a drenagem do fluido inflamatório e hemorrágico, promovendo revascularização e melhor orientação das fibras colágenas. Sendo utilizado na fase aguda da doença, mediante avaliação prévia através de exame ultrassonográfico, a técnica pode ser muito útil e eficaz no cumprimento de suas funções (ALVES et al., 2002).

\section{Prevenção}

A prevenção da tendinite está diretamente relacionada com a redução dos fatores de riscos, casqueamento adequado e preventivo, além de evitar superfícies perigosas para os animais. Ainda é importante ressaltar, que os equinos em treinamento regrado, com frequência de lesões nos tendões, devem ser observados rigorosamente, empregando-se cuidados pós-treino, como duchas e colocação de ligas nos membros (THOMASSIAN, 2005; LAVOIE; HINCHCLIFE, 2008).

$\mathrm{O}$ tratamento adequado dos animais acometidos, promovendo descanso e monitoramento ultrassonográfico adequado, ajuda a evitar reincidências, prolongando assim a vida atlética do animal (THOMASSIAN, 2005; LAVOIE; HINCHCLIFE, 2008). Outra forma de prevenção da tendinite está no cuidado com o animal ainda potro, tendo em vista que esses animais quando criados livres em pastagens, possuem tendão mais forte e elástico em comparação aos que foram criados em baias ou submetidos a treinamentos. O treinamento e os exercícios excessivos podem prejudicar permanentemente a biomecânica e função dos tendões flexores no potro (BAXTER, 2020).

\section{CONSIDERAÇÕES FINAIS}

A tendinite é considerada uma afecção de grande importância na clínica médica de equinos, podendo ocasionar perdas econômicas aos proprietários, devido à redução no desempenho dos animais. Além disso, as lesões tendíneas decorrentes de esforço excessivo são capazes de prejudicar a vida atlética do animal acometido e se não tratada adequadamente, pode acarretar o aposento precoce destes animais.

Portanto, o diagnóstico precoce da doença com estabelecimento do tratamento adequado pode reduzir o risco de sequelas e recidivas, influenciando assim, a melhora clínica do paciente. Ademais, é possível garantir que o animal possa desempenhar todo seu potencial genético, apresentando possibilidade de retorno à vida esportiva. 


\section{REFERÊNCIAS}

ALLGAYER, M. I. G. F. Crioterapia em equinos atletas. Revista Mais Equina, v. 13, n. 82, p. 36-38, 2019.

ALLGAYER, M. I. G. F. Ultrassom terapêutico. Revista Mais Equina, v. 14, n. 92, p. 3638, 2020.

ALVARENGA, M. L. Tratamento de tendinite de equino com células-tronco mesenquimais associadas à fisioterapia: relato de caso. Revista Mais Equina, v. 13, $n$. 85, p. 40-41, 2019.

ALVARENGA, M. L. PRP: O que é e como funciona. Revista Mais Equina, v.14, n. 91, p. 32, 2020.

ANITUA, E; ANDIA; I; ARDANZA, B; NURDEN, P; NURDEN, A. Autologous platelet source of proteins for healing and tissue regeneration. Thrombosis and Haemostasis, v. 91, n. 1, p 4-15, 2004. Disponível em: < https://pubmed.ncbi.nlm.nih.gov/14691563/ >. Doi: 10.1160/TH03-07-0440.

ALVES, A. L. G., NICOLETTI, J. L. M., THOMASSIAN, A., HUSSNI, C. A.; WATANABE, M. J. Tratamento cirúrgico splitting nas tendinites agudas experimentais em eqüinos. Archives of Veterinary Science, v. 7, n. 2, 2002. Disponível em: < https://revistas.ufpr.br/veterinary/article/view/3980 >. Doi: http://dx.doi.org/10.5380/avs.v7i2.3980

BANDEIRA, A. L. ; PINHEIRO, M. ; ROCHA, M. V. DA ; VAGO, P. B. Use of laserterapy in tissue repair in equine. Ciência Animal, v. 30, N. 1, p.77-84, 2020. Disponível em: $<$ http://www.uece.br/cienciaanimal/index.php?option=com_do

cman\&task=doc_view\&gid=743\&tmpl=component\&format=raw\&ltemid=157>.

BAXTER, G. M. Manual of equine lameness. 7ed. lowa: Wiley Blackwell, p. 585-590, 2020.

BECCATI, F.; PEPE, M.; ANTINORI, L.; PASCUCCI, L.; CHIARADIA, E.; MANDARA, M. T. Sympathetic Innervation and Adrenergic Receptors in Equine Deep Digital Flexor Tendinopathy: Preliminary Results. Journal of Comparative Pathology, 163, p. 33-37, 2018.

Disponível em:

https://www.sciencedirect.com/science/article/abs/pii/S0021997518301555?via\%3Dihub >. Doi: 10.1016/j.jcpa.2018.07.005.

BERNER, D. Diagnostic imaging of tendinopathies of the superficial flexor tendon in horses. The Veterinary record, London, v. 181, n. 24, p. 652, 2017. Disponível em: < https://pubmed.ncbi.nlm.nih.gov/29246992/ >. Doi: 10.1136/vr.j5746. 
BISCIOTTI, G. N.; VOLPI, P. Tendonitis, Tendinosis, or Tendinopathy. Sports and Traumatology, p. 1-19, 2016. Disponível em: < http://link-springer-com-443.webvpn. fjmu.edu.cn/chapter/10.1007\%2F978-3-319-33234-5_1 >. Doi:10.1007/978-3-319-32 34-5_1.

BONILLA-GUTIÉRREZ, A. F.; LÓPEZ, C.; CARMONA, J. U. Regenerative therapies for the treatment of tenodesmic injuries in horses. Journal of Equine Veterinary Science, v. 73, p. 139-147, 2019. 2 Disponível em: <https://www.sciencedirect.com/science/article/abs/pii/S0737080618306890>. Doi: https://doi.org/10.1016/j.jevs.2018.12.010

BRANDÃO, J; ALVARENGA, M; PFEIFER, J; DOS SANTOS, V.; FONSECA-ALVES, C, et al., Allogeneic mesenchymal stem cell transplantation in healthy equine superficial digital flexor tendon: A study of the local inflammatory response. Veteromary Science, ed.118, p.423-40, 2018. Disponível em: <https://www.sciencedirect.com/science/article/abs/pii/S0034528817310287>. Doi: https://doi.org/10.1016/j.rvsc.2018.03.012.

CHEDID, H. S.; Matheus, M. M. Tendinites e desmites. Eqquality, 2016. Disponível em <https://www.eqqualitycce.com/textos-tendinites-desmites $>$. Acesso em: 23 de junho de 2020.

COLBATH, A; FRISBIE, D; DOW, S; KISIDAY, J.; McLLWRAITH, W. et al. Equine Models for the Investigation of Mesenchymal Stem Cell Therapies in Orthopaedic Disease. Operative Techniques in Sports Medicine, Philadelphia, v. 25, n. 1, p. 41 49, 2017. Disponível em: < https://www.sciencedirect.com/science/article/abs/pii/S1060187216300636> Doi: https://doi.org/10.1053/j.otsm.2016.12.007

COOK, C. R. Ultrasound imaging of the musculoskeletal system. Vet Clin Small Animal, v. 46, e. 3, p. 355-37, 2016. Disponível em: <https://www.sciencedirect.co $\mathrm{m} / \mathrm{science/article/abs/pii/S0195561615001783?via \% 3Dihub> \text {. }}$ https://doi.org/10.1016/j.cvsm.2015.12.001

DAHLGREN, L. A. Regenerative Medicine Therapies for Equine Wound Management. Veterinary Clinics of North America, v. 34, p. 605-620, 2018. Disponível em: < https://www.sciencedirect.com/science/article/abs/pii/S0749073918300506?via\%3Dihub > Doi: https://doi.org/10.1016/j.cveq.2018.07.009

GEBUREK, F.; GAUS, M.; VAN SCHIE, H. T. M.; ROHN, K.; STADLER, P. M. Effect of intralesional platelet-rich plasma (PRP) treatment on clinical and ultrasonographic parameters in equine naturally occurring superficial digital flexor tendinopathies - a randomized prospective controlled clinical trial. BMC Vet Res, 2016. Disponível em: 
<https://www.ncbi.nlm.nih.gov/pmc/articles/PMC7235160/> Doi: 10.1186/s12917-0160826-1.

GIUNTA, K.; DONNELL, J. R.; DONNELL, A. D.; FRISBIE, D. D. Prospective randomized comparison of platelet rich plasma to extracorporeal shockwave therapy for treatment of proximal suspensory pain in western performance horses. Research in Veterinary Science, v. 126, p. 38-44, 2019. Doi: 10.1016/j.rvsc.2019.07.020

JARDIM, M. Tendinopatia Patelar. Essfisionline, v. 1, n. 4, p. 31-47, 2005. Disponível em: < http://www.ifisionline.ips.pt/media/essfisionline/vol1n4.pdf>.

JOHNSTON, D. E. Tendons, skeletal muscles, and ligaments in health and disease. In: NEWTON, C. D.; NUNAMAKER, D. M. (Eds.). Textbook of small animal orthopaedics. Philadelphia : Lippincott, cap.4. p.65-76.1985.

JUNQUEIRA, L. C.; CARNEIRO, J. Histologia básica. 12 ed. Rio de Janeiro: Guanabara Koogan, 1990.

KANEPS, A. J. Practical rehabilitation and physical therapy for the general practitioner. Veterinary Clinics of North America: Equine Practice, v. 32, p. 167-180, 2016. Disponível em: <https://www.sciencedirect.com/science/article/abs/pii/SO 749073915000863?via\%3Dihub> Doi: http://dx.doi.org/10.1016/j.cveq.2015.12.001

KNIGHT, K.L. Crioterapia no tratamento das lesões esportivas. 1 ed. Barueri: Manoli, p. 20-25, 2000.

$\mathrm{KOCH}$, D.W; GOODRICH, L.R. Principles of therapy for lameness. In: BAXTER, G.M. Manual of equine lameness. 7ed. lowa: Wiley Blackwell, 2020. p. 881-883.

LAVOIE, J.; HINCHCLIFF, K. Blackwekks's five-minute veterinary consult: Equine. 2 ed. Iwoa, USA: Office, 2008.

MACHADO, E. C.; CAMPEBELL, R. C. Tendinite do flexor digital superficial em equinos: tratamento com plasma rico em plaquetas, v. 2, n. 1, 2015. Disponível em: $<$ http://revista.faciplac.edu.br/index.php/Revet/article/view/116>.

MCGOWAN, C. M.; COTTRIALL, S. Introduction to Equine Physical Therapy and Rehabilitation. Vet Clin North Am Equine Pract, v. 32, n. 1, p. 1-12, 2016. Disponível em: $\quad<h t t p s: / / w w w . s c i e n c e d i r e c t . c o m / s c i e n c e / a r t i c l e / a b s / p i i / S 07490739$ 15000917?via\%3Dihub> Doi:10.1016/j.cveq.2015.12.006

MCLLWRAITH, C. W. Tendinitis in Horses, MSD Manual Veterinary Manual, 2015. Disponível em: <https://www.msdvetmanual.com/musculoskeletal-system/lameness-inhorses/tendinitis-in-horses>. Acessado em 06 de out. de 2020. 
NAVIAUX, J. Cavalo na saúde e na doença. 4 ed. California: Roca, 1988.

NORDIN, M.; FRANKEL, V. H. Biomecânica básica do sistema musculoesquelético. 3. ed. Rio de Janeiro: Ed. Guanabara Koogan, 2003.

ORTVED, K. F. Regenerative Medicine and Rehabilitation for Tendinous and Ligamentous Injuries in Sport Horses. Vet Clin North Am Equine Pract, v. 34, n. 2, p. 359-373, 2018. Disponível em: <https://www.sciencedirect.com/science/article/ abs/pii/S0749073918300257?via\%3Dihub> Doi:10.1016/j.cveq.2018.04.012

PAYNE, J. T., TOMLINSOM, J. L. Composition, structure, and function of muscle, tendon and ligament. In: BOJRAB, M.J. (Ed.). Disease mechanisms in small animal surgery. 2 ed. Philadelphi a: Lea \& Febiber, 1993. cap.95. p.656-662.

PEACOCK, E. E., Van WINKLE, W. Wound repair. 2 ed. Philadelphia: Saunders, chap.8: Repair of tendons and restoration of gliding function: p.367-464.1976.

REDDING, W.R. Ultrasound. In: BAXTER, G.M. Manual of equine lameness. 7ed. lowa: Wiley Blackwell, p. 301-335.2020.

SCHRAMME, M; SEGARD-WEISSE, E. Magnetic Resonance Imaging. In: BAXTER, G.M. Manual of equine lameness. 7ed. lowa: Wiley Blackwell, 2020. p. 387-424.

SHOJAEE, A.; PARHAM, A. Strategies of tenogenic differentiation of equine stem cells for tendon repair: current status and challenges. Stem Cell Res Ther, v. 10, n. 181, p. 1-13, 2019. Disponível em: <https://www.ncbi.nlm.nih.gov/pmc/articles/PMC6 582602/> Doi: 10.1186 / s13287-019-1291-0

SOUSA, N.R; LUNA, S.P.L.; PUZZIGATTI, D.; MARTINS, M.T.A; POSSEBON, F.S.; AGUIAR, A.C.S. Relação do tipo e local de lesões ortopédicas com a atividade física em equinos. O Ciência Rural, v. 47, n. 2, 2017. Doi: 10.1590/0103-8478cr20151218

SPINOSA, H. S.; GORNIAK, S. L.; BERNARDI, M. M. Farmacologia Aplicada à Medicina Veterinária. 4를. Edo de Janeiro: Guanabara Koogan, 2006.

STERARD, S.K.T; GOODRICH, L.R. Intralesional. In: BAXTER, G.M. Manual of equine lameness. 7ed. lowa: Wiley Blackwell, 2020. p. 896-898.

TORRES-TORRILLAS, M.; RUBIO, M.; DAMIA, E.; CUERVO, B.; DEL ROMERO, A. et al. Adipose-Derived Mesenchymal Stem Cells: A Promising Tool in the Treatment of Musculoskeletal Diseases. International Journal of Molecular Sciences, v. 20, n. 12, 2019. Disponível em: <https://www.ncbi.nlm.nih.gov/pmc/articles/PMC6627452 />. Doi:10.3390/ijms20123105

THOMASSIAN, A. Enfermidade dos cavalos. 4 ed. São Paulo: Livraria Varela, 2005. 
TURNER, T.A. Thermography. In: BAXTER, G.M. Manual of equine lameness. 7ed. lowa: Wiley Blackwell, p. 585-590.2020.

WHITING, W.; ZERNICKE, R. F. Biomecânica da lesão musculoesquelética. Rio de Janeiro: Guanabara Koogan, 2001.

WITTE, S.; DEDMAN, C.; HARRISS, F.; KELLY, G.; CHANG, Y. M.; WITTE, T. H. Comparison of treatment outcomes for superficial digital flexor tendonitis in National Hunt racehorses. The Veterinary Journal, v. 116, p. 157-163, 2016. Disponível em: <https://www.sciencedirect.com/science/article/abs/pii/S1090023316301174?via\%3Dihu b>. Doi:10.1016/j.tvjl.2016.08.003

ZACHARY, J. F. Bases em patologia veterinária / James F. Zachary; tradução Alexandre Aldighieri Soares et al.; revisão técnica Paulo Maiorka et al. - 6.ed.- Rio de Janeiro: Elsevier, 2018. 